ARTICLE

DOI: $10.1038 / \mathrm{s} 41467-017-02152-5$

\title{
Silica-grafted ionic liquids for revealing the respective charging behaviors of cations and anions in supercapacitors
}

\author{
Qingyun Dou ${ }^{1,2}$, Lingyang Liư ${ }^{1,2}$, Bingjun Yang ${ }^{1}$, Junwei Lang $^{1} \&$ Xingbin Yan (10 ${ }^{1}$
}

\begin{abstract}
Supercapacitors based on activated carbon electrodes and ionic liquids as electrolytes are capable of storing charge through the electrosorption of ions on porous carbons and represent important energy storage devices with high power delivery/uptake. Various computational and instrumental methods have been developed to understand the ion storage behavior, however, techniques that can probe various cations and anions of ionic liquids separately remain lacking. Here, we report an approach to monitoring cations and anions independently by using silica nanoparticle-grafted ionic liquids, in which ions attaching to silica nanoparticle cannot access activated carbon pores upon charging, whereas free counter-ions can. Aided by this strategy, conventional electrochemical characterizations allow the direct measurement of the respective capacitance contributions and acting potential windows of different ions. Moreover, coupled with electrochemical quartz crystal microbalance, this method can provide unprecedented insight into the underlying electrochemistry.
\end{abstract}

\footnotetext{
${ }^{1}$ Laboratory of Clean Energy Chemistry and Materials, State Key Laboratory of Solid Lubrication, Lanzhou Institute of Chemical Physics, Lanzhou 730000 China. ${ }^{2}$ University of Chinese Academy of Sciences, Beijing 100080 China. Correspondence and requests for materials should be addressed to X.Y. (email: xbyan@licp.cas.cn)
} 
E ectrochemical double-layer capacitors (EDLCs, also called supercapacitors) based on porous activated carbons (ACs) are promising energy storage devices owing to their high power density, fast charge/discharge capability, and ultra-long cycle life $^{1-7}$. In EDLCs, electrolytes, like AC electrodes, are useful in directly determining the overall performance of the devices $^{7-12}$. The calculation formula of energy density $(E=1 / 2$ $C V^{2}$, where $E$ is the energy density, $C$ is the specific capacitance, and $V$ is the operating potential window) indicates that the $E$ of the device greatly depends on the $V$ of electrolytes. Ionic liquids (ILs) have wider operating potential windows, lower vapor pressures, and better chemical and thermal stability than aqueous electrolytes and are thus frequently used as non-aqueous electrolytes $^{9-13}$. Furthermore, ILs exhibit remarkably increased energy densities and wide applicable temperature ranges; thus, they are considered promising electrolytes for EDLCs ${ }^{8-11,14,15}$.

ILs are composed of organic cations and organic or inorganic anions, and numerous cations and anions can be selected for IL combinations ${ }^{10,16,17}$. These cations and anions have distinctly asymmetric chemical structures, and thus the positive and negative electrodes of EDLCs in IL electrolytes exhibit uneven working potential distributions and variable electrochemical behaviors ${ }^{14,18-21}$. Furthermore, the charge storage capacities of ACs in EDLCs can be directly affected by the types and molecular structures of cations and anions of ILs ${ }^{14,19,20}$. Therefore, studying the effects of the intrinsic structures of cations and anions on the capacitive properties of ACs and determining the real charge storage mechanisms of EDLCs in IL electrolytes are necessary for the proper selection of ILs and rational design of highperformance EDLCs ${ }^{22,23}$.

Many computational simulations and instrumental analysis methods have been developed for the characterization of the storage mechanisms of ACs of EDLCs in ILs. The charge storage behaviors of AC electrodes in ILs can be understood from the theoretical level through computational simulations; the capacitance and ion dynamics of EDLCs strongly depend on factors, such as relative pore or ion size ${ }^{19,24-26}$, confinement effect $^{26-28}$, and ionophilic/ionophobic pores ${ }^{28-30}$. Simulations must undergo necessary simplifications such that simulation time and accuracy are effectively balanced. Consequently, they usually do not include all details of complex porous/and electronic structures of ACs at experimental conditions. By contrast, reported instrumental analysis methods using infrared (IR) spectroscopy $y^{31,32}$, small-angle neutron scattering (SANS) ${ }^{33-35}$, electrochemical quartz crystal microbalance $(\mathrm{EQCM})^{36-44}$, and nuclear magnetic resonance $(\mathrm{NMR})^{44-50}$ are effective techniques and can be effectively used for the observation of variations in ion concentration in AC pores during charging or discharging; additionally, purely perm-selective behaviors (adsorption of counter-ions, which have an electric charge opposite to that of electrodes) and ion swapping behaviors (adsorption of counter-ions, together with the desorption of coions, which have the same electric charge as that of electrodes) occur during the polarization of AC electrodes ${ }^{22,23}$. Cations or anions of an IL can be individually monitored through an IR technique because each type of ions has its own characteristic signal in the IR spectrum. Meanwhile, SANS can be used for the direct characterization of ions in differently sized pores, and the dynamic capability of EQCM allows real-time measuring of changes in electrode mass during charging. NMR is an effective detection technique with excellent elemental selectivity. The peak area in an NMR spectrum is proportional to the corresponding ion concentration. Moreover, NMR can be used for the selectively monitoring of in-pore ions with resonances shifting to a frequency lower than that of ex-pore ions. Therefore, in-pore cations and anions can be separately characterized and their concentrations can be fully quantified through NMR. Nevertheless, IR, SANS, EQCM, and NMR require specialized and expensive instruments, and have their respective analytical limitations ${ }^{22}$. Thus, for the in-depth understanding of the energy storage mechanisms of EDLCs, universal experimental methods that can characterize the influences of various cations and anions of ILs on the charge storage of ACs need to be developed.

EDLCs use porous ACs with high specific surface area and uniform pore size distribution. When only one type of ion (either cation or anion) of an IL is allowed to enter carbon pores, the respective electrochemical behaviors of cations and anions in carbon pores can be analyzed. To this end, we develop an organic synthesis strategy for silica nanoparticle-grafted ILs to realize this idea (Fig. 1). In these synthetic $\mathrm{SiO}_{2}$-grafted ILs, only one ion is free, and the ion used for balancing the charge is directly attached to silica nanoparticles. Moreover, ACs are selected as study samples. Their pore sizes are less than the diameter of silica nanoparticles. We find that, when the $\mathrm{SiO}_{2}$-grafted ILs are used as electrolytes for AC electrodes, the ions covalently attached to silica nanoparticles are restricted to access to the $\mathrm{AC}$ pores, and only the free ions are able to enter the pores during charging or discharging (Fig. 1d). Thus, free ions in pores can be quantitatively analyzed through conventional electrochemical tests. By using AC electrodes, we are able to directly measure the capacitance contributed by cations and anions, and we find that each ion is adsorbed or desorbed within its own specific potential window during charge storage. Combination of the measurement results of respective charging behaviors of cations and anions with the results of EQCM investigation implies that purely perm-selective behavior, which is determined by the nature of ions, is dominant at a high polarized window, and only counter-ion adsorption contributes capacitance; by contrast, perm selectivity and ion swapping both occur at a low polarized window, which is determined by the competition between counter-ions and co-ions.

\section{Results}

Material synthesis and characterization. Four types of $\mathrm{SiO}_{2}$ grafted ILs were synthesized through the aforementioned organic synthesis methods. Methyl imidazolium cation $\left(\mathrm{MIM}^{+}\right)^{51,52}$ and trifluoromethanesulfonyl imide anion $\left(\mathrm{NTf}^{-}\right)$were covalently attached to $7 \mathrm{~nm}$ commercial silica nanoparticles (LUDOX SM-30 colloidal silica, Aldrich). Meanwhile, $\mathrm{MIM}^{+}$or $\mathrm{NTf}^{-}$ possesses an ionic moiety that balances the charge of free ions and can bear a carbon chain that can attach to $\mathrm{SiO}_{2}$ nanoparticles. Synthetic $\mathrm{SiO}_{2}-\mathrm{MIM}^{+}$was combined either with bis(trifluoromethanesulfonyl) imide $\left(\mathrm{NTf}_{2}{ }^{-}\right)$or hexafluorophosphate $\left(\mathrm{PF}_{6}{ }^{-}\right)$, and synthetic $\mathrm{SiO}_{2}-\mathrm{NTf}^{-}$was combined with either 1-butyl-3-methylimidazolium $\left(\mathrm{BMIM}^{+}\right)$and tetrabutylammonium $\left(\mathrm{NBu}_{4}^{+}\right)$(Fig. 1a).

Figure 2 shows the reaction steps for synthesizing $\mathrm{SiO}_{2}$-grafted ILs, namely, $\mathrm{SiO}_{2}-\mathrm{IL}^{-\mathrm{NTf}_{2}}(\mathbf{1}), \mathrm{SiO}_{2}-\mathrm{IL}^{-\mathrm{PF}_{6}}$ (2), $\mathrm{SiO}_{2}$-IL-BMIM (3), and $\mathrm{SiO}_{2}-\mathrm{IL}-\mathrm{NBu}_{4}$ (4) (see methods). The main issue of this synthetic method was the preparation of key intermediate products, particularly $\mathrm{SiO}_{2}-\mathrm{MIM}-\mathrm{Cl}(5)$ and $\mathrm{SiO}_{2}$-NTf-Li (6) for the attachment of ions $\left(\mathrm{MIM}^{+}\right.$and $\left.\mathrm{NTf}^{-}\right)$to $\mathrm{SiO}_{2}$ nanoparticles. To obtain compound 9 , we actuated a quaternization reaction between (3-chloropropyl)trimethoxysilane (7) and 1-methylimidazole (8). The produced compound 9 was subsequently attached to the $\mathrm{SiO}_{2}$ nanoparticles by a condensation reaction for the production of $\mathrm{SiO}_{2}-\mathrm{MIM}-\mathrm{Cl}$ (5). Compound 5 was subjected to an ion exchange with $\operatorname{LiNTf}_{2}(\mathbf{1 0})$ and $\operatorname{LiPF}_{6}(\mathbf{1 1})$ and successfully converted into $\mathrm{SiO}_{2}-\mathrm{IL}_{-} \mathrm{NTf}_{2}(\mathbf{1})$ and $\mathrm{SiO}_{2}$-IL$\mathrm{PF}_{6}$ (2), respectively. For the preparation of $\mathrm{SiO}_{2}-\mathrm{NTf}-\mathrm{Li}(6)$, compound 12 was first converted into compound 13 via trifluoromethanesulfonylation, followed by lithiation. Then, compound 13 was attached to the $\mathrm{SiO}_{2}$ nanoparticles for $\mathrm{SiO}_{2}-$ 
a

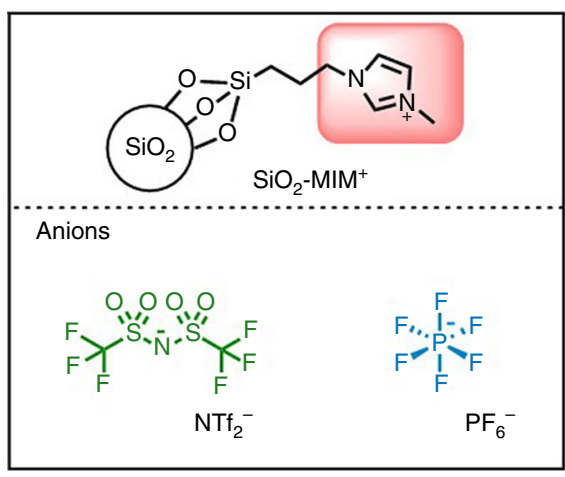

b

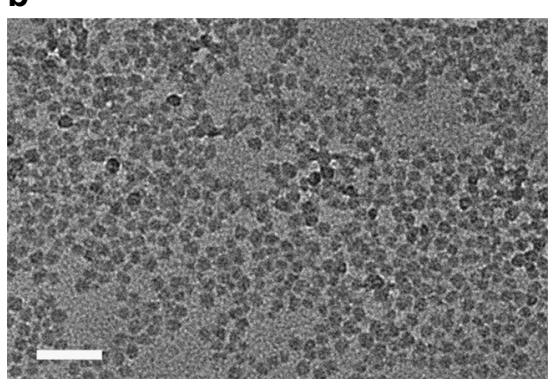

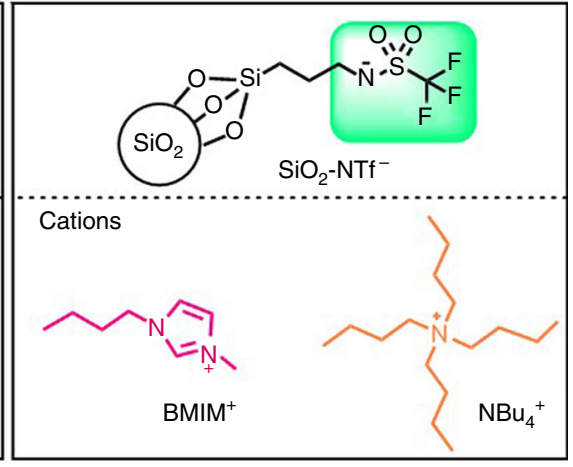

C

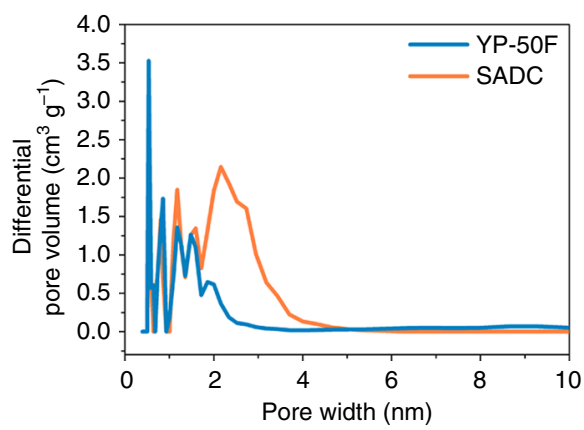

d
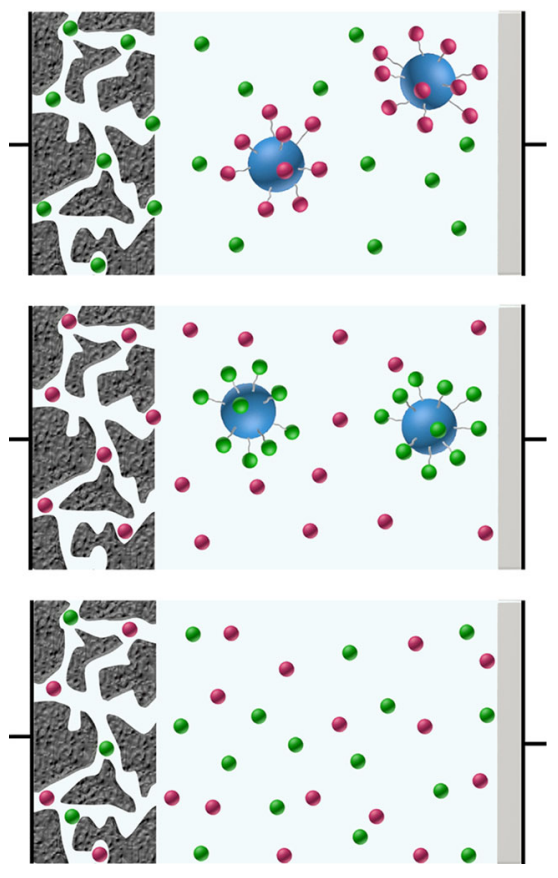

Fig. 1 Schematic of the strategy for respectively characterizing the charging behavior of cations and anions of ionic liquids in electrochemical double-layer capacitors (EDLCs). a Structures of cations, anions, and silica nanoparticle-grafted ions. b Transmission electron micrograph of silica nanoparticles with a uniform diameter of $7 \mathrm{~nm}$. Scale bar, $50 \mathrm{~nm}$. c Pore size distributions of two activated carbons, which indicate that the pore sizes in two activated carbons are smaller than the diameter of silica nanoparticles. $\mathbf{d}$ Schematic of charge storage of activated carbon electrodes during polarization in different types of ionic liquids: silica nanoparticle-grafted cations and free anions (top), silica nanoparticle-grafted anions and free cations (middle), conventional cations and anions (bottom). Big blue balls represent silica nanoparticles, small wine balls represent cations, and green balls represent anions

NTf-Li (6) production. Lithium ion $\left(\mathrm{Li}^{+}\right)$in $\mathrm{SiO}_{2}$-NTf-Li (6) was substituted with $\mathrm{BMIM}^{+}$(14) or $\mathrm{NBu}_{4}{ }^{+}$(15) through ion exchange for $\mathrm{SiO}_{2}$-IL-BMIM (3) and $\mathrm{SiO}_{2}$-IL-NBu production.

The chemical structures and purity of the synthesized $\mathrm{SiO}_{2}-$ grafted ILs were confirmed by ${ }^{1} \mathrm{H}$ NMR and ${ }^{19} \mathrm{~F}$ NMR. The results indicated that $\mathrm{MIM}^{+}$and $\mathrm{NTf}^{-}$were successfully attached to the $\mathrm{SiO}_{2}$ nanoparticles (Supplementary Figs. 3-8). Energydispersive X-ray spectroscopy (Supplementary Fig. 13) and inductively coupled plasma optical emission spectroscopy (see Supplementary Information) results verified that the absence of $\mathrm{Cl}, \mathrm{Br}$, or $\mathrm{Li}$ in the $\mathrm{SiO}_{2}$-grafted ILs, suggesting that excess salt ( $\mathrm{LiCl}$ or $\mathrm{LiBr}$ ) was completely removed after ion exchange. The above measurements confirmed that only one type of ion was free in each $\mathrm{SiO}_{2}$-grafted IL. The IR spectra further demonstrated the existence of characteristic bands for the $\mathrm{SiO}_{2}$-grafted ILs (Supplementary Fig. 14), indicating the successful grafting of IL molecules on the $\mathrm{SiO}_{2}$ nanoparticles. The ion concentrations (the ratio of the mole number of ions to the mass of the corresponding $\mathrm{SiO}_{2}$-grafted IL) determined by an internal standard method (Supplementary Figs. 9-12) in the four $\mathrm{SiO}_{2}$-grafted ILs were $0.93,0.95,0.86$, and $0.67 \mathrm{mmol} \mathrm{g}^{-1}$. Thermogravimetric analysis results indicated that the $\mathrm{SiO}_{2}$-grafted ILs were thermally stable up to $200^{\circ} \mathrm{C}$ and their mass losses at $800^{\circ} \mathrm{C}$ were $49.6,35.1,37.4$, and $40.6 \mathrm{wt} \%$ (Supplementary Fig. 15).

Electrochemical measurements. A commercially available AC (YP-50F, Kuraray Chemical, Japan) was used as electrode (Supplementary Fig. 1). Four synthesized $\mathrm{SiO}_{2}$-grafted ILs and the corresponding ILs or organic salts (BMIM-NTf $\mathrm{B}_{2}, \mathrm{BMIM}-\mathrm{PF}_{6}$, $\mathrm{NBu}_{4}-\mathrm{NTf}_{2}$, and $\mathrm{NBu}_{4}-\mathrm{PF}_{6}$ ) dissolved in anhydrous propylene carbonate (PC) with the same concentration of $0.25 \mathrm{M}$ were used as electrolytes (Supplementary Fig. 16). The electrochemical behavior of AC electrodes in electrolytes was characterized in a closed three-electrode system. Figure 3 shows the cyclic voltammetry (CV) curves of the YP-50F electrode in four $\mathrm{SiO}_{2}$-grafted IL electrolytes at the same scan rate $\left(5 \mathrm{mV} \mathrm{s}^{-1}\right)$. The $\mathrm{CV}$ curves of $\mathrm{SiO}_{2}$-IL-BMIM within different operating potential windows (Fig. 3a), which should actually exhibit the sorption property of $\mathrm{BMIM}^{+}$because only it can freely enter the pores of YP-50F, all showed that the specific capacitance rapidly decreased when the electrode was positively polarized to $\sim 0.9 \mathrm{~V} / \mathrm{ref}$ (the maximum slope was around this potential). This rapid decrease in capacitance indicated that the upper acting potential for the capacitance contribution of $\mathrm{BMIM}^{+}$was $\sim 0.9 \mathrm{~V} /$ ref (Supplementary Note 1 , Supplementary Figs. 17 and 18). The CV curves of $\mathrm{SiO}_{2}-\mathrm{IL}_{-} \mathrm{NBu}_{4}$ exhibited a similar feature (Fig. 3c). Thus, the upper acting potential for the capacitance contribution of $\mathrm{NBu}_{4}{ }^{+}$was $\sim 1.0 \mathrm{~V} /$ ref. The rapid decrease in capacitance was also observed in the CV curves of $\mathrm{SiO}_{2}-\mathrm{IL}^{-\mathrm{NTf}_{2}}$ (Fig. 3b) and $\mathrm{SiO}_{2}-\mathrm{IL}^{-} \mathrm{PF}_{6}$ (Fig. 3d), but the decrease occurred at negatively polarized directions $(-0.1$ $\mathrm{V} / \mathrm{ref}$ for $\mathrm{SiO}_{2}-\mathrm{IL}_{-}-\mathrm{NTf}_{2}$ and $0.1 \mathrm{~V} / \mathrm{ref}$ for $\mathrm{SiO}_{2}-\mathrm{IL}_{2}-\mathrm{PF}_{6}$ ). The lower acting potentials for the capacitance contributions of anions were $\sim-0.1 \mathrm{~V} /$ ref for $\mathrm{NTf}_{2}{ }^{-}$and $\sim 0.1 \mathrm{~V} /$ ref for $\mathrm{PF}_{6}{ }^{-}$. Comparisons between the CV curves of two cations with the same operating potential windows and between those of two anions were conducted. The results showed that the capacitance contribution of $\mathrm{BMIM}^{+}$was larger than that of $\mathrm{NBu}_{4}{ }^{+}$for the YP-50F electrode, and that of $\mathrm{NTf}_{2}^{-}$was larger than that of $\mathrm{PF}_{6}{ }^{-}$(Supplementary 

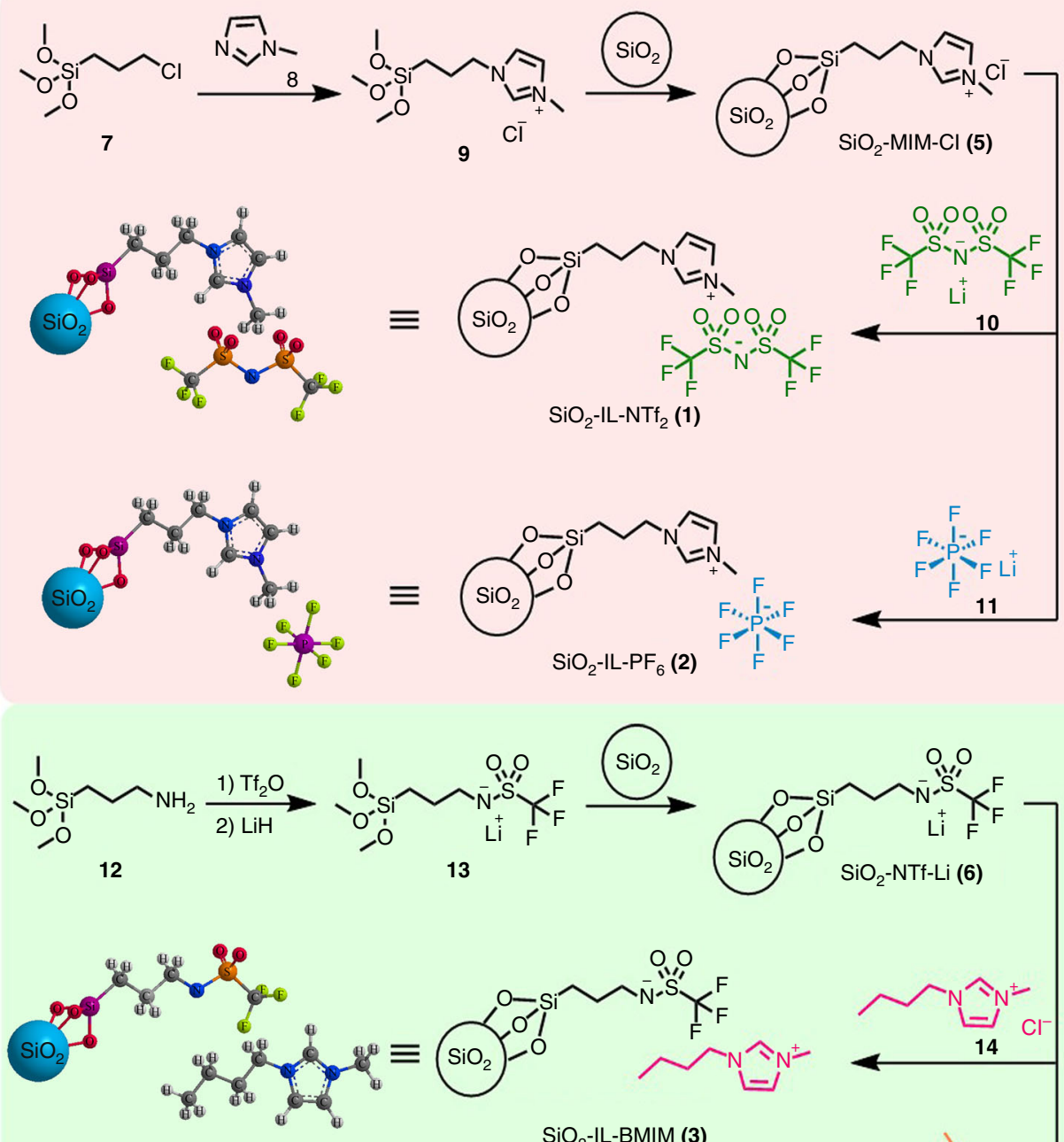

$\mathrm{SiO}_{2}-\mathrm{IL}-\mathrm{BMIM}(3)$
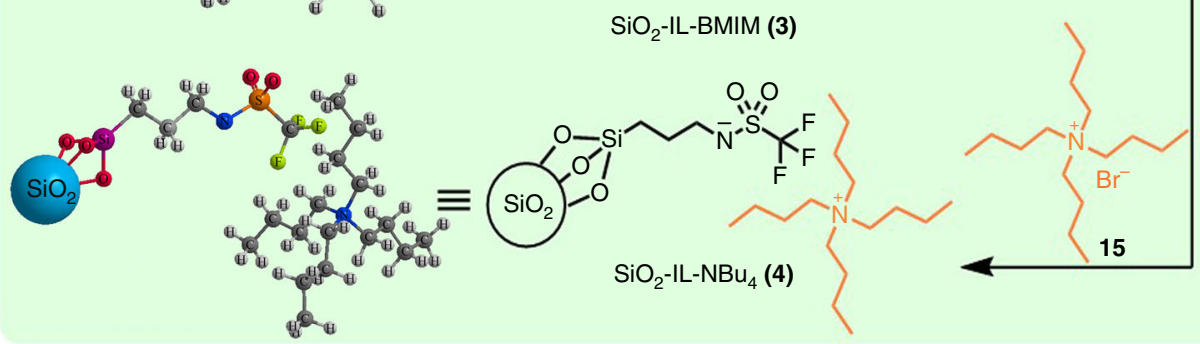

Fig. 2 Synthesis of four silica nanoparticle-grafted ionic liquids ( $\mathrm{SiO}_{2}$-grafted ILs). Methyl imidazolium cation (MIM+) and trifluoromethanesulfonyl imide anion $\left(\mathrm{NTf}^{-}\right)$were firstly covalently grafted to silica nanoparticles to synthesize the key intermediate products $\mathrm{SiO}_{2}-\mathrm{MIM}^{+}$and $\mathrm{SiO}_{2}-\mathrm{NTf}^{-}$. Synthetic $\mathrm{SiO}_{2}{ }^{-}$ $\mathrm{MIM}^{+}$was combined either with bis(trifluoromethanesulfonyl) imide $\left(\mathrm{NTf}_{2}^{-}\right)$or hexafluorophosphate $\left(\mathrm{PF}_{6}{ }^{-}\right)$, and synthetic $\mathrm{SiO}_{2}-\mathrm{NTf}^{-}$was combined with either 1-butyl-3-methylimidazolium $\left(\mathrm{BMIM}^{+}\right)$and tetrabutylammonium $\left(\mathrm{NBu}_{4}^{+}\right)$through ion exchange to obtain $\mathrm{SiO}_{2}-\mathrm{IL}_{-} \mathrm{NTf}_{2}(\mathbf{1}), \mathrm{SiO}_{2}-\mathrm{IL}_{-}-\mathrm{PF}_{6}(\mathbf{2}), \mathrm{SiO}_{2}-\mathrm{IL}_{-}$ $\mathrm{BMIM}(\mathbf{3})$, and $\mathrm{SiO}_{2}-\mathrm{IL}-\mathrm{NBu}_{4}(\mathbf{4})$

Fig. 19). The difference may be attributed to the differences between the compared ions with respect to size and chemical structure, which may have affected the interface interaction between the ions and pore surfaces of carbon electrodes ${ }^{14,18}$. Meanwhile, some studies reported that one type ions can solely contribute to charge storage mechanisms ${ }^{39,40}$. The CV curves of $\mathrm{SiO}_{2}-\mathrm{IL}-\mathrm{NTf}_{2}$ and $\mathrm{SiO}_{2}-\mathrm{IL}_{-}-\mathrm{PF}_{6}$ were similar to that of another commercial AC (YP-17, Kuraray Chemical, Japan) electrode in tetraoctylammonium tetrafluoroborate $\left(\mathrm{TOA}-\mathrm{BF}_{4}\right) \mathrm{IL}^{39}$, in which the charge at the negatively polarized electrode rapidly decreases because the bulky $1.12 \mathrm{~nm} \mathrm{TOA}^{+}$cations are inaccessible to most of the carbon pores. Basing on this similarity, we concluded that ions attached to $\mathrm{SiO}_{2}$ nanoparticles were indeed restricted out of the pores of YP-50F during the charging process.
We summed the $\mathrm{CV}$ curves of $\mathrm{SiO}_{2}$-IL-BMIM and $\mathrm{SiO}_{2}$-IL$\mathrm{NTf}_{2}, \mathrm{SiO}_{2}$-IL-BMIM and $\mathrm{SiO}_{2}-\mathrm{IL}_{-} \mathrm{PF}_{6}, \mathrm{SiO}_{2}-\mathrm{IL}_{-} \mathrm{NBu}_{4}$ and $\mathrm{SiO}_{2}-$ IL-NTf 2 , and $\mathrm{SiO}_{2}-\mathrm{IL}_{-}-\mathrm{NBu}_{4}$ and $\mathrm{SiO}_{2}-\mathrm{IL}_{-} \mathrm{PF}_{6}$ to obtain the summed $\mathrm{CV}$ curves of the YP-50F electrode in four organic electrolytes (BMIM-NTf $, \mathrm{BMIM}_{2} \mathrm{PF}_{6}, \mathrm{NBu}_{4}-\mathrm{NTf}_{2}$, and $\mathrm{NBu}_{4}$ $\mathrm{PF}_{6}$ ), as shown in Fig. $4 \mathrm{a}-\mathrm{d}$. The summed $\mathrm{CV}$ curves (blue dotted lines) represented a perfect state, in which all cations and anions fully contributed their capacitance. On the two sides of each highly polarized region, a purely adsorptive mechanism should be observed. In particular, only the counter-ions contributed capacitance (light red, orange, blue, and green regions). Taking Fig. $4 \mathrm{a}$ as an example, the capacitance only originated from the contribution of $\mathrm{BMIM}^{+}$at a negatively polarized potential window (below $-0.1 \mathrm{~V} / \mathrm{ref}$ ); and at the high positively polarized 
a

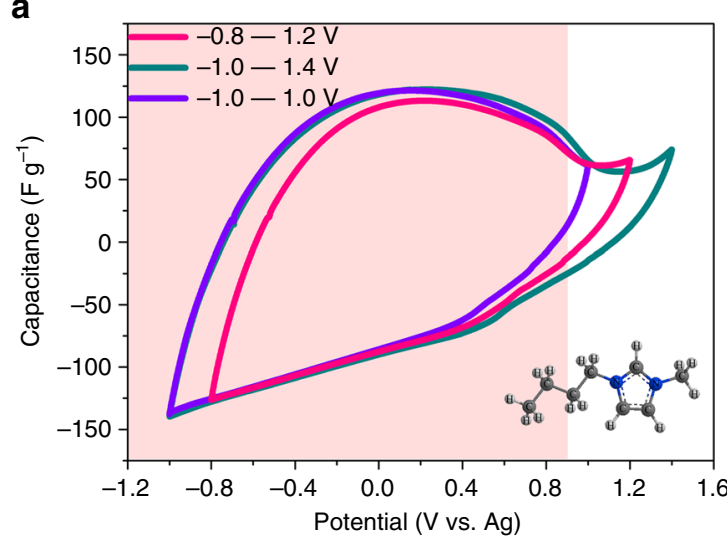

b

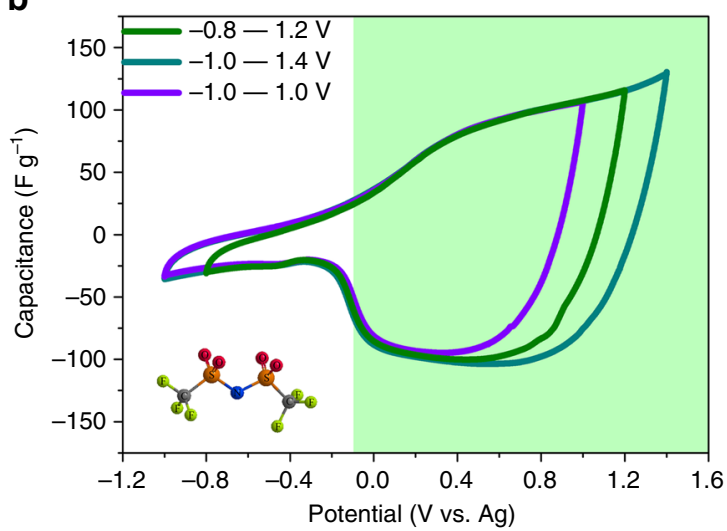

d

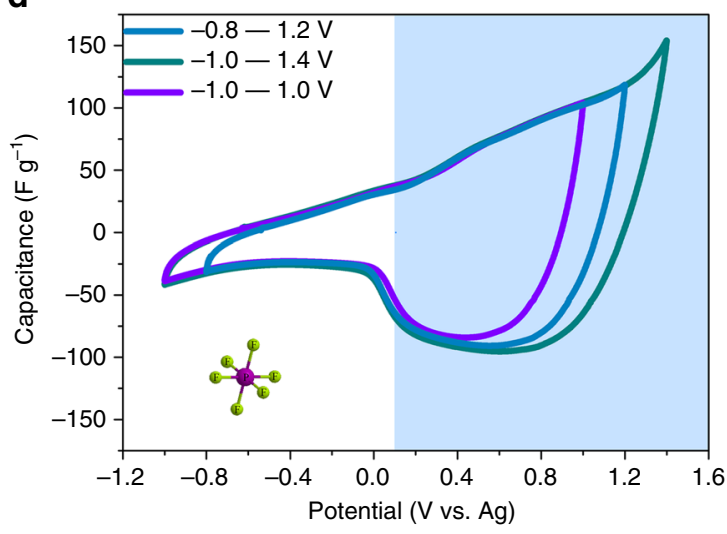

Fig. 3 Cyclic voltammetry (CV) curves of YP-5OF electrode in four $\mathrm{SiO}_{2}$-grafted ILs with the same concentration of $0.25 \mathrm{M}$ in propylene carbonate (PC). a $\mathrm{SiO}_{2}-\mathrm{IL}-\mathrm{BMIM}, \mathbf{b} \mathrm{SiO}_{2}-\mathrm{IL}_{-} \mathrm{NTf}_{2}, \mathbf{c} \mathrm{SiO}_{2}-\mathrm{IL}_{\mathrm{NBu}}$, and $\mathbf{d} \mathrm{SiO}_{2}-\mathrm{IL}^{-}-\mathrm{PF}_{6}$. The curves were scanned within different operating potential windows with the same scan rate of $5 \mathrm{mV} \mathrm{s}^{-1}$
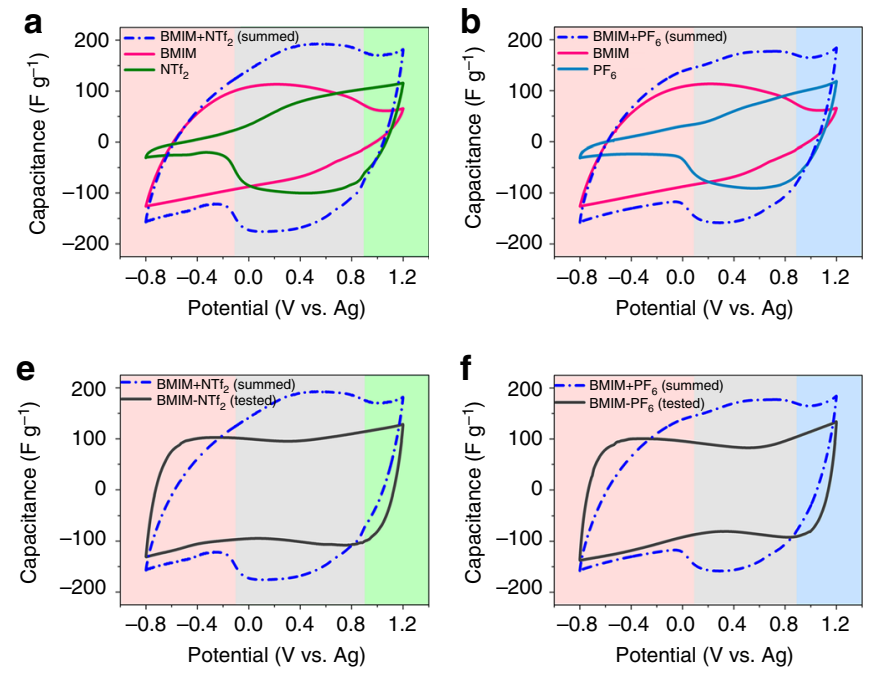
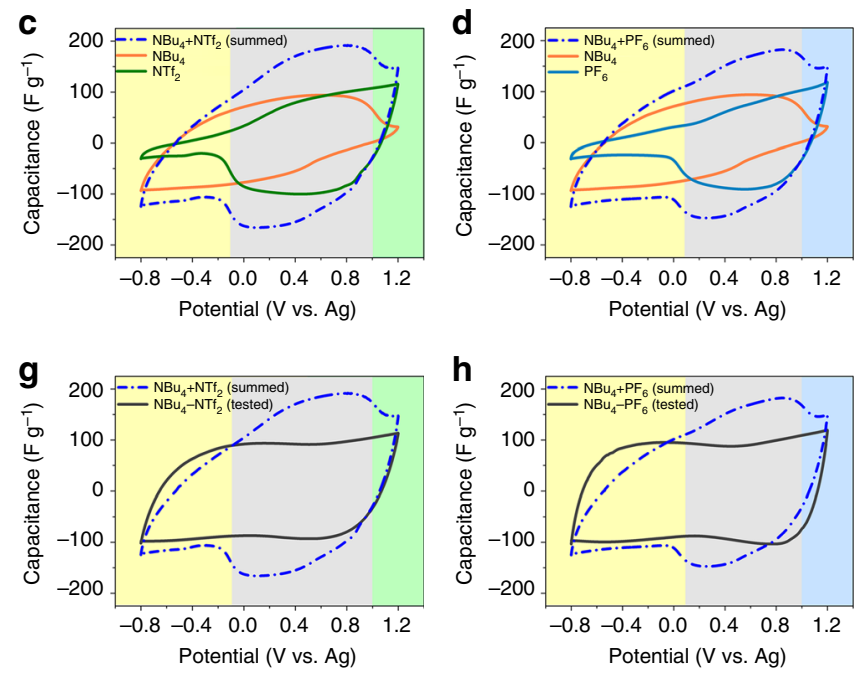

Fig. 4 Comparison of the summed CV curves with the real CV curves. Summed cyclic voltammetry (CV) curves of YP-50F electrode in four electrolytes by

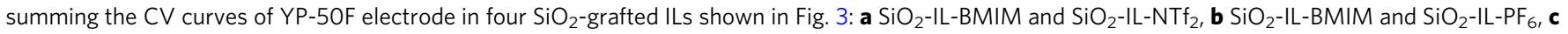
$\mathrm{SiO}_{2}-\mathrm{IL}_{-} \mathrm{NBu}_{4}$ and $\mathrm{SiO}_{2}-\mathrm{IL}-\mathrm{NTf}_{2}, \mathbf{d} \mathrm{SiO}_{2}-\mathrm{IL}_{\mathrm{NBu}}$ and $\mathrm{SiO}_{2}-\mathrm{IL}_{4}-\mathrm{PF}_{6}$. Summed CV curves and real CV curves of YP-50F electrode in four corresponding

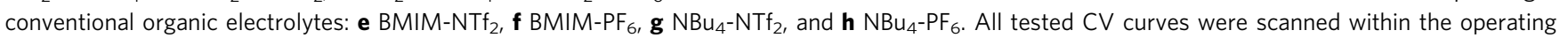
potential window of $-0.8 \mathrm{~V}$ to $1.2 \mathrm{~V} / \mathrm{ref}$ with the same scan rate of $5 \mathrm{mV} \mathrm{s}^{-1}$. The organic electrolytes had the same concentration of $0.25 \mathrm{M}$ in propylene carbonate $(\mathrm{PC})$

potential window (above $0.9 \mathrm{~V} / \mathrm{ref}$ ) the capacitance was only contributed by $\mathrm{NTf}_{2}^{-}$. At a middle potential window of -0.1 to $0.9 \mathrm{~V} /$ ref (gray region), both $\mathrm{BMIM}^{+}$and $\mathrm{NTf}_{2}{ }^{-}$presented charge storage, and the capacitance value of the summed CV curve was larger than that of the CV curve in $\mathrm{SiO}_{2}$-IL-BMIM or $\mathrm{SiO}_{2}$-IL$\mathrm{NTf}_{2}$. However, is it true? To determine whether the two ions at the middle region can promote each other and thus exhibit summed capacitance, we tested the actual CV curves of the four 
a

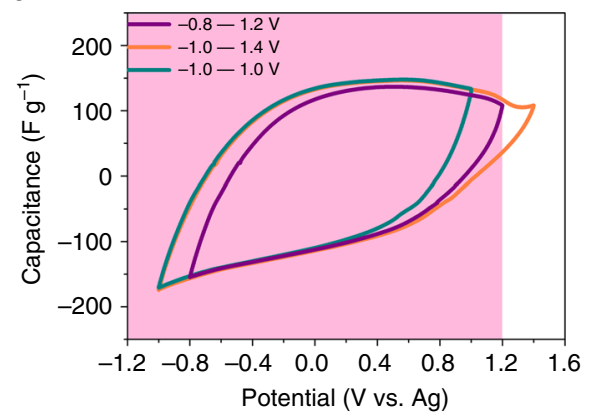

b

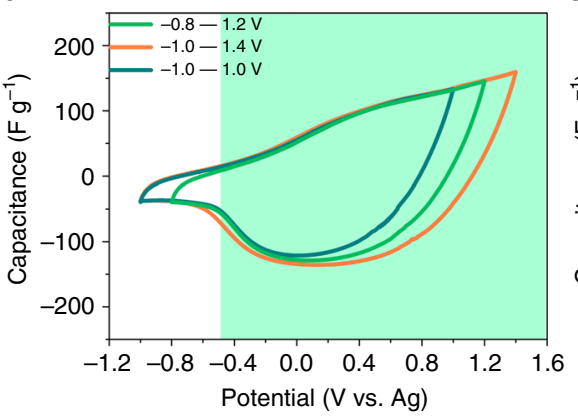

C

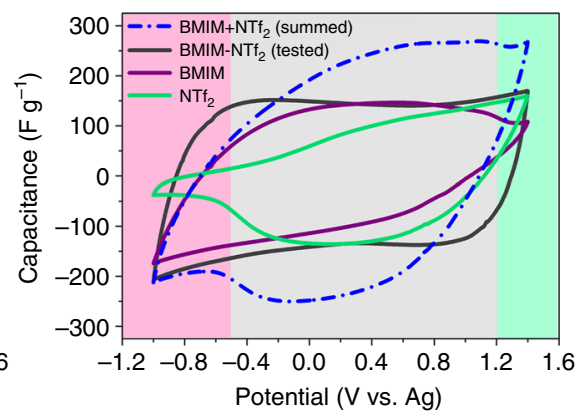

Fig. 5 Electrochemical characterization of sodium alginate-derived activated carbon (SADC) electrode. Cyclic voltammetry (CV) curves in a SiO ${ }_{2}-\mathrm{IL}-\mathrm{BMIM}$ and $\mathbf{b} \mathrm{SiO}_{2}-\mathrm{IL}_{\mathrm{NTf}}$ with the same concentration of $0.25 \mathrm{M}$ in propylene carbonate (PC). The curves were scanned within different operating potential windows with the same scan rate of $5 \mathrm{mV} \mathrm{s}^{-1}$. c Comparison between the summed and real CV curves of SADC electrode in BMIM-NTf ${ }_{2}$ at an operating potential window of -1.0 to $1.4 \mathrm{~V} / \mathrm{ref}$

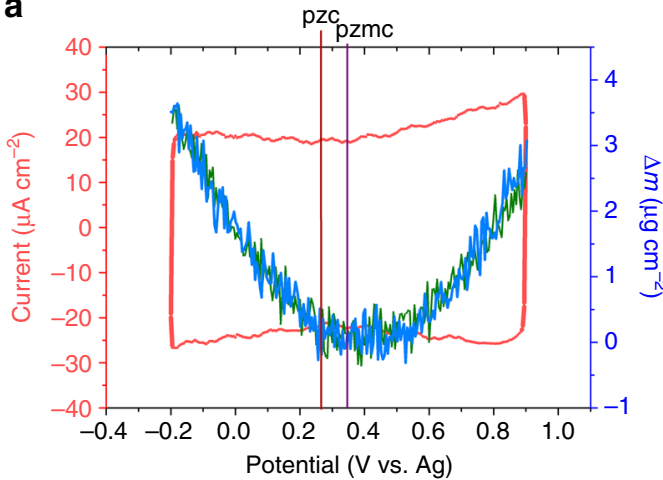

b

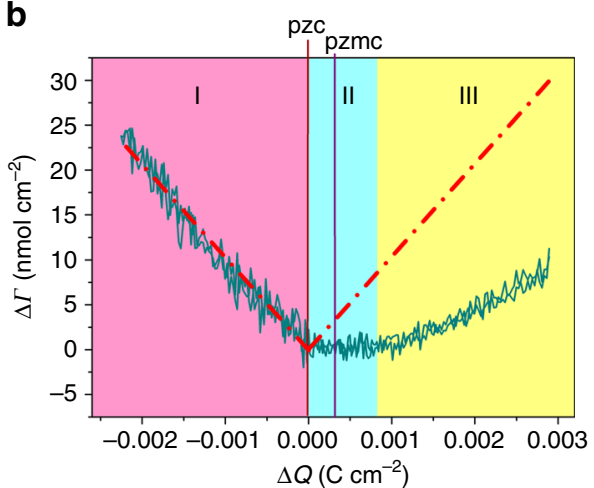

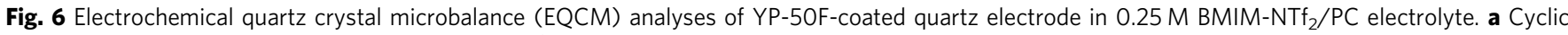
voltammetry $(\mathrm{CV})$ curve with a scan rate of $5 \mathrm{mV} \mathrm{s}^{-1}$ and the corresponding EQCM mass change. $\mathbf{b}$ lon population change as a function of charge density during polarization. Cyan solid line represents the experimental ion population change. Red dashed line is the theoretical ion population change based on perm-selective behavior

conventional ILs, which all exhibited a nearly rectangular shape (black lines in Fig. 4e-h), indicating the typical EDLC behavior of AC electrode. The summed curves were compared with actual curves (Fig. 4e-h), and the results showed that the capacitance values of the summed $\mathrm{CV}$ curves were significantly larger than that of the actual CV curves at low polarized regions (middle gray regions, defined on the basis of the acting potential of each $\mathrm{SiO}_{2}$ grafted IL shown in Fig. 3). The summed CV curves represented the ideal sum of the respective sorption contribution of cations and anions on carbon surfaces, and the actual CV curves represented the real overall sorption behavior of cations and anions on the same carbon surfaces. Therefore, the comparison results indicated that the cations and anions competed with each other within the middle region. In addition, the capacitance of the summed curves was smaller than that of the conventional electrolytes upon the reversal of the potential possibly because of the decreased ionic conductivity of the $\mathrm{SiO}_{2}$-grafted ILs (Supplementary Table 1). The decrease may be caused by the restricted movement of the free ions of the $\mathrm{SiO}_{2}$-grafted ILs because of the nearly immobile $\mathrm{SiO}_{2}$ nanoparticles.

After separately monitoring the charging behavior of cations and anions of ILs using YP-50F electrode as the study subject, we further verified the feasibility of this strategy for other ACs. The homemade sodium alginate-derived AC (denoted as SADC) was selected as study sample. Figure $5 \mathrm{a}, \mathrm{b}$ show the $\mathrm{CV}$ curves of SADC in $\mathrm{SiO}_{2}$-IL-BMIM and $\mathrm{SiO}_{2}$-IL-NTf ${ }_{2}$ ILs, both of which had the same concentration of $0.25 \mathrm{M}$ in PC. Figure $5 \mathrm{c}$ shows the summed and real CV curves of the SADC in the BMIM-NTf 2 /PC electrolyte. Similar CV shapes appeared for the SADC electrode. $\mathrm{BMIM}^{+}$dominated at the potential below $-0.5 \mathrm{~V} / \mathrm{ref}, \mathrm{NTf}_{2}{ }^{-}$ dominated at the potential above $1.2 \mathrm{~V} / \mathrm{ref}$, and $\mathrm{BMIM}^{+}$and $\mathrm{NTf}_{2}{ }^{-}$competed at the middle potential window of -0.5 to $1.2 \mathrm{~V} /$ ref. The results of the CV comparison between the YP-50F and SADC electrodes (Supplementary Fig. 20) indicated that latter had higher capacitance than former in the BMIM-NTf electrolyte system. It because the SADC had higher Brunauer-Emmett-Teller surface area than the YP-50F (Supplementary Figs. 1 and 2).

As mentioned before, changes in electrode mass during dynamic ion charging can be measured in real time through $\mathrm{EQCM}^{36-44}$. Thus, in situ EQCM investigation was conducted to study the specific charge mechanisms of cations and anions within the competitive potential window indicated above. Figure 6a shows the $\mathrm{CV}$ curve and the simultaneous mass change ( $\Delta m$; calculated from the frequency response change of EQCM experiment through Sauerbrey's equation (see Supplementary Information)) of YP-50F-coated quartz (as working electrode; Supplementary Note 2, Supplementary Fig. 22) in a BMIM-NTf ${ }_{2} /$ PC electrolyte within an operating potential window of -0.2 to $0.9 \mathrm{~V} /$ ref. Potential window was selected by a chronoamperometry test ${ }^{44}$ (Supplementary Note 3, Supplementary Figs. 23 and 24). Moreover, when the YP-50F-coated quartz electrode was cycled between $-0.2 \mathrm{~V}$ and $0.9 \mathrm{~V} / \mathrm{ref}$, the resonance width change $(\Delta W)$ should be much smaller than the simultaneous resonance frequency change $(\Delta f$; Supplementary Note 4, Supplementary Fig. 25$)^{37,41}$. In Fig. 6 a, at potential scans ranging from $0.9 \mathrm{~V} / \mathrm{ref}$ 


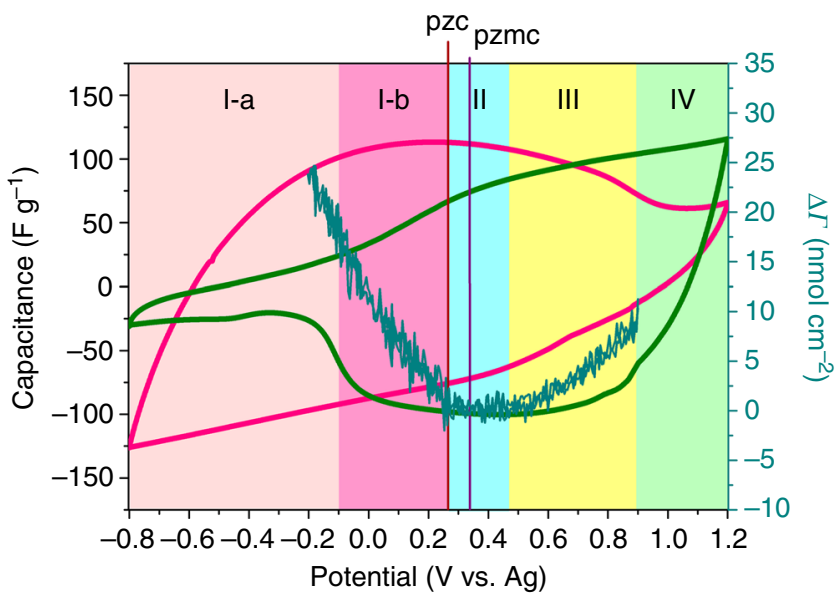

Fig. 7 Combination of electrochemical quartz crystal microbalance (EQCM) data with the cyclic voltammetry (CV) curves shown in Fig. $4 a$

to $-0.2 \mathrm{~V} / \mathrm{ref}$, the mass change (olive line) typically showed a $\mathrm{V}$ shape. At the subsequent potential back scanning from $-0.2 \mathrm{~V} / \mathrm{ref}$ to $0.9 \mathrm{~V} / \mathrm{ref}$, the mass change (blue line) was nearly coincidental with the previous one, indicating the reversibility of the current experiment. The potential of zero mass change (pzmc), which corresponded to the minimum mass change, was close to $0.34 \mathrm{~V} /$ ref. The evaluated potential of zero charge (pzc) of $0.27 \mathrm{~V} /$ ref was shifted to the left with respect to pzmc (Supplementary Fig. 21).

Figure $6 \mathrm{~b}$ shows that the ion population change $(\Delta \Gamma)$ is a function of charge density $(\Delta Q$; calculated by integration of the related $\mathrm{CV}$ ). The cyan line represents the experimental ion population change obtained by dividing the mass change by the molecular weight of the ion, and the red dashed line is the theoretical ion population change calculated by assuming adsorption of solely counter-ions with the use of Faraday's law (see Supplementary Information). During the negative polarization from pzc $(\Delta Q<0)$, the experimental ion population change was nearly equal to the theoretical one, implying that the charge on the negatively polarized electrode was solely balanced by the principle adsorption of counter-ions $\left(\mathrm{BMIM}^{+}\right)$, and no solvent was involved ${ }^{37,38,43}$ (Fig. 6b, domain I). During the positive polarization from pzc $(\Delta Q>0)$, the experimental ion population change exhibited a flat minimum close to pzmc at a low charge density (Fig. 6b, domain II) and demonstrated an ion swapping behavior, that is, co-ion $\left(\mathrm{BMIM}^{+}\right)$desorption and counter-ion $\left(\mathrm{NTf}_{2}{ }^{-}\right)$adsorption were both involved in the charge storage mechanism 37,43 . The shift of pzc to the left with respect to pzmc indicated that desorption of co-ions $\left(\mathrm{BMIM}^{+}\right)$played a dominant role in the potential between pzc and $\mathrm{pzmc}^{42}$. At a high charge density (Fig. 6b, domain III), changes in the experimental ion population continuously increased, and the slope gradually approached the theoretical one, illustrating that the role of coion desorption diminished, whereas counter-ions played a dominant role in the charge storage process ${ }^{42,43}$.

The EQCM results were further combined with the results obtained in the CV curves of $\mathrm{SiO}_{2}$-grdfted ILs $\left(\mathrm{SiO}_{2}\right.$-IL-BMIM (red curve), $\mathrm{SiO}_{2}$-IL-NTf 2 (green curve)) to yield an in-depth understanding of the charging mechanism of carbon YP-50F in BMIM-NTf 2 /PC (Fig. 7). At highly negatively and positively polarized regions (below $-0.1 \mathrm{~V} / \mathrm{ref}$ and above $0.9 \mathrm{~V} / \mathrm{ref}$ ), only perm-selective behavior was determined because solely one type of two ions $\left(\mathrm{BMIM}^{+}\right.$or $\mathrm{NTf}_{2}^{-}$) exhibited charging behaviors in the two regions. Within the intermediate potential window of -0.1 to $0.9 \mathrm{~V} / \mathrm{ref}$, perm selectivity and ion swapping both occurred and were determined by the competition between cations $\left(\mathrm{BMIM}^{+}\right)$and anions $\left(\mathrm{NTf}_{2}^{-}\right)$. Specifically, at negative polarization (the potential was below pzc), solely perm-selective behavior was observed. In domain I-a (potential below $-0.1 \mathrm{~V} /$ ref), the comparison of CV curves of $\mathrm{SiO}_{2}$-IL-BMIM and $\mathrm{SiO}_{2}$-IL$\mathrm{NTf}_{2}$ indicated that the perm-selective behavior was determined by the intrinsic characteristic of ions, and the counter-ions $\left(\mathrm{BMIM}^{+}\right)$alone stored charge, whereas co-ions $\left(\mathrm{NTf}_{2}{ }^{-}\right)$did not. In domain I-b (potential from $-0.1 \mathrm{~V} /$ ref to $0.27 \mathrm{~V} /$ ref), counterions $\left(\mathrm{BMIM}^{+}\right)$and co-ions $\left(\mathrm{NTf}_{2}^{-}\right)$presented competition, and the EQCM result demonstrated that the capacitance only originated from the adsorption of counter-ions $\left(\mathrm{BMIM}^{+}\right)$. At positive polarization (the potential was above pzc), the EQCM experiment revealed that at the low positively polarized region $(0.27 \mathrm{~V} /$ ref to $0.9 \mathrm{~V} / \mathrm{ref}$, domains II and III), the adsorption of counter-ions $\left(\mathrm{NTf}_{2}^{-}\right)$and desorption of co-ions $\left(\mathrm{BMIM}^{+}\right)$both contributed capacitance, and the role of counter-ion $\left(\mathrm{NTf}_{2}{ }^{-}\right)$ adsorption became evident as the polarization degree increased. At the highly positively polarized region (above $0.9 \mathrm{~V} / \mathrm{ref}$, domain $\mathrm{IV})$, only the adsorption of the counter-ions $\left(\mathrm{NTf}_{2}{ }^{-}\right)$was involved.

\section{Discussion}

In summary, we demonstrated a method to separately monitor cations $\left(\mathrm{BMIM}^{+}, \mathrm{NBu}_{4}{ }^{+}\right)$and anions $\left(\mathrm{NTf}_{2}{ }^{-}, \mathrm{PF}_{6}{ }^{-}\right)$in $\mathrm{AC}$ pores by utilizing four $\mathrm{SiO}_{2}$-grafted ILs, which were successfully prepared by organic synthesis. The charging behaviors of $\mathrm{BMIM}^{+}$, $\mathrm{NBu}_{4}{ }^{+}, \mathrm{NTf}_{2}^{-}$, and $\mathrm{PF}_{6}^{-}$at different potential states can be directly measured through conventional $\mathrm{CV}$ tests and by ensuring that only one type of ion enters the AC pores. The CV results of cations and anions indicated that capacitance originated from the contribution of the counter-ions or from the competition between counter-ions and co-ions, which were determined by the polarization of AC electrodes. An extensive understanding of the detailed charge storage mechanism of AC in BMIM-NTf $\mathrm{N}_{2}$ system was achieved by further combining the relative results of $\mathrm{BMIM}^{+}$ and $\mathrm{NTf}_{2}{ }^{-}$with the data obtained from the EQCM experiment. The perm-selective behavior alone was observed at the highly polarized potential regions (below $-0.1 \mathrm{~V} /$ ref and above $0.9 \mathrm{~V} /$ ref), whereas perm-selective and ion swapping behaviors were both observed at the low polarized potential regions (within the intermediate potential window of -0.1 to $0.9 \mathrm{~V} / \mathrm{ref}$ ), as determined by the competition between cations and anions. This work provided an effective way to respectively characterize the charging behavior of cations and anions of ILs in ACs. We can imagine the characterization of more types of ions can be achieved by utilizing the corresponding $\mathrm{SiO}_{2}$-grafted ILs. Our work is of great significance to the rational choice of IL electrolytes and efficient construction of high-performance EDLCs.

\section{Methods}

Preparation of silica nanoparticle-grafted ionic liquids. $\mathrm{SiO}_{2}-\mathrm{MIM}-\mathrm{Cl}$ (5). 1 methylimidazole $(\mathbf{8}, 8.0 \mathrm{~mL}, 0.1 \mathrm{mmol})$ was added in a solution of (3-chloropropyl) trimethoxysilane $(7,18.2 \mathrm{~mL}, 0.1 \mathrm{mmol})$ in dimethylformamide (DMF, $120 \mathrm{~mL}$ ) and the mixture was stirred at $80^{\circ} \mathrm{C}$ for $48 \mathrm{~h}$. After the reaction was completed, the solvent was evaporated under vacuum. The resulting viscous liquid was dissolved in $\mathrm{H}_{2} \mathrm{O}$ and the organic byproducts were extracted with ether $\left(\mathrm{Et}_{2} \mathrm{O}\right)$ and dichloromethane $\left(\mathrm{CH}_{2} \mathrm{Cl}_{2}\right)$. The aqueous phase was evaporated under vacuum and the product 9 was obtained as yellow oil. Subsequently, an aqueous suspension of silica nanoparticles $(200 \mathrm{~mL}, 2.5 \mathrm{wt} \%)$ was added in an aqueous solution of 9 (5 $\mathrm{mL}, 1.0 \mathrm{~mol} / \mathrm{L}$ ) slowly. The mixture was stirred at $80^{\circ} \mathrm{C}$ for $12 \mathrm{~h}$ to afford $\mathrm{SiO}_{2}-$ $\mathrm{MIM}-\mathrm{Cl}(5)$ as a white suspension without further purification.

$\mathrm{SiO}_{2}$-NTf- $\mathrm{Li}(6)$. The trifluoromethanesulfonic anhydride $\left(\mathrm{Tf}_{2} \mathrm{O}, 16.9 \mathrm{~mL}, 0.1\right.$ $\mathrm{mmol}$ ) was slowly added in a solution of 3-(trimethoxysilyl)propan-1-amine (12, $17.5 \mathrm{~mL}, 0.1 \mathrm{mmol})$ and triethylamine $\left(\mathrm{Et}_{3} \mathrm{~N}, 28 \mathrm{~mL}, 0.2 \mathrm{mmol}\right)$ in dried $\mathrm{CH}_{2} \mathrm{Cl}_{2}$ $(150 \mathrm{~mL})$ at $-78^{\circ} \mathrm{C}$ under dry argon atmosphere. The mixture was stirred for $1 \mathrm{~h}$ and then heated to room temperature. An aqueous of potassium hydroxide $(\mathrm{KOH}$, $17.1 \mathrm{~g}, 0.3 \mathrm{mmol}$ ) was then added in this mixture and the resulting organic byproducts were extracted with $\mathrm{CH}_{2} \mathrm{Cl}_{2}$. The aqueous phase was neutralized with hydrochloric acid $(\mathrm{HCl}, 80 \mathrm{~mL}, 4 \mathrm{~mol} / \mathrm{L})$ and extracted with ethyl acetate. The organic phase was dried by magnesium sulfate $\left(\mathrm{MgSO}_{4}\right)$ and then concentrated to 
afford a colorless oil. This oil was dissolved in anhydrous acetonitrile $\left(\mathrm{CH}_{3} \mathrm{CN}, 150\right.$ $\mathrm{mL}$ ) and lithium hydride ( $\mathrm{LiH}, 1.2 \mathrm{~g}, 0.15 \mathrm{mmol}$ ) was then added in the solution slowly at $0{ }^{\circ} \mathrm{C}$. The resulting solid byproducts and excess $\mathrm{LiH}$ were removed by filtration. After the solvent was evaporated under vacuum, the product $\mathbf{1 3}$ was obtained as white solid. Subsequently, an aqueous suspension of silica nanoparticles $(200 \mathrm{~mL}, 2.5 \mathrm{wt} \%)$ was added in a solution of $13(15 \mathrm{~mL}, 1.0 \mathrm{~mol} / \mathrm{L}$ in $\mathrm{H}_{2} \mathrm{O}$ ) slowly. The mixture was stirred at $80^{\circ} \mathrm{C}$ for $12 \mathrm{~h}$ to afford $\mathrm{SiO}_{2}-\mathrm{MIM}-\mathrm{Cl}(\mathbf{6})$ as a white suspension without further purification.

$\mathrm{SiO}_{2}$ - $\mathrm{IL}^{-} \mathrm{NTf}_{2}(\mathbf{1})$. The suspension of $\mathrm{SiO}_{2}-\mathrm{MIM}-\mathrm{Cl}(5)$ was added in an aqueous solution of $\operatorname{LiNTf}_{2}(\mathbf{1 0}, 1.05$ equiv. to $\mathbf{9}$ in previous step). After fully mixing, the resulting precipitation was separated by centrifugation. The solid product was purified by washing with acetone/ $\mathrm{H}_{2} \mathrm{O}(\mathrm{v} / \mathrm{v}=3 / 2)$ and centrifugation. The final traces of $\mathrm{H}_{2} \mathrm{O}$ were removed by lyophilized under vacuum to afford the product $\mathrm{SiO}_{2}-\mathrm{IL}_{-}-\mathrm{NTf}_{2}(\mathbf{1})$

$\mathrm{SiO}_{2}-\mathrm{IL}_{2}-\mathrm{PF}_{6}(2)$. The suspension of $\mathrm{SiO}_{2}-\mathrm{MIM}-\mathrm{Cl}(5)$ was added in an aqueous solution of $\operatorname{LiPF}_{6}$ (11, 1.05 equiv. to 9 in previous step). After fully mixing, the precipitated solid was separated by centrifugation. The solid product was purified by washing with acetone $/ \mathrm{H}_{2} \mathrm{O}(\mathrm{v} / \mathrm{v}=3 / 2)$ and centrifugation. The final traces of $\mathrm{H}_{2} \mathrm{O}$ were removed by lyophilized under vacuum to afford the product $\mathrm{SiO}_{2}-\mathrm{IL}_{-}-\mathrm{PF}_{6}(2)$.

$\mathrm{SiO}_{2}$-IL-BMIM (3). The suspension of $\mathrm{SiO}_{2}$-NTf- $\mathrm{Li}(\mathbf{6})$ and $\mathrm{CH}_{2} \mathrm{Cl}_{2}(2 \mathrm{~mL})$ were added in an aqueous solution of $\mathrm{BMIMCl}(\mathbf{1 4}, 1.05$ equiv. to $\mathbf{1 3}$ in previous step). After fully mixing, the precipitated solid was separated by centrifugation. The solid product was purified by washing with $\mathrm{H}_{2} \mathrm{O}$ and centrifugation. The final traces of $\mathrm{H}_{2} \mathrm{O}$ were removed by lyophilized under vacuum to afford the product $\mathrm{SiO}_{2}$-IL-BMIM (3).

$\mathrm{SiO}_{2}$-IL-NBu 4 (4). The suspension of $\mathrm{SiO}_{2}$-NTf-Li (6) was added an aqueous solution of $\mathrm{NBu}_{4} \mathrm{Cl}(\mathbf{1 5}, 1.05$ equiv. to $\mathbf{1 3}$ in previous step). After fully mixing, the precipitated solid was separated by centrifugation. The product was purified by washing with acetone/petroleum ether $(\mathrm{v} / \mathrm{v}=2 / 3)$ and centrifugation, then washing again with $\mathrm{H}_{2} \mathrm{O}$ and centrifugation. The final traces of $\mathrm{H}_{2} \mathrm{O}$ were removed by lyophilized under vacuum to afford the product $\mathrm{SiO}_{2}-\mathrm{IL}^{-\mathrm{NBu}_{4}}(\mathbf{4})$.

Material characterization. ${ }^{1} \mathrm{H}$ NMR and ${ }^{19} \mathrm{~F}$ NMR spectra were recorded in $d$ DMSO solution on a Bruker $400 \mathrm{MHz}$ spectrometer. The spectral data were reported in ppm and calibrated by using DMSO $(2.50 \mathrm{ppm})$ as internal reference for ${ }^{1} \mathrm{H}$ NMR. The nitrogen adsorption-desorption isotherm was measured on an ASAP $2020 \mathrm{M}$ porosimeter (Micromeritics) at $77 \mathrm{~K}$. The specific surface area (SSA) was calculated using the Brunauer-Emmett-Teller (BET) method and the pore size distribution (PSD) was calculated from the isotherm using the

Barrett-Joyner-Halenda (BJH) method. Transmission electron microscopy (TEM) was conducted using a JEOL 2100 FEG microscope at $200 \mathrm{keV}$. Scanning electron microscope (SEM) was conducted using a JEOL JSM $6701 \mathrm{~F}$ microscope. Energy dispersive X-ray spectroscopy (EDS) was conducted using a JSM-5601LV microscope. Inductively coupled plasma optical emission spectroscopy (ICP-OES) was conducted using a Leeman Prodigy7 spectrometer. Fourier transform infrared (FTIR) spectra were recorded using a Nexus 870 FTIR spectrometer. Thermogravimetric analysis (TGA) was carried out using a STA $449 \mathrm{C}$ thermal analyzer at a heating rate of $10^{\circ} \mathrm{C} \mathrm{min}-1$ in air atmosphere. The electrical conductivity of IL electrolytes was measured by using a Mettler Toledo FE30 FiveEasy conductivity meter.

Electrochemical measurements. Electrochemical CV tests were carried out using an electrochemical workstation (CHI440C, Shanghai, China) in a closed threeelectrode system, assembled in a glovebox under argon, with a silver disk as the quasi-reference electrode, a platinum foil $\left(1 \times 1 \mathrm{~cm}^{2}\right)$ as the counter electrode and a carbon electrode as the working electrode. The carbon electrodes were prepared from YP-50F and SADC: $95 \mathrm{wt} \%$ carbon powder $(2.0 \mathrm{mg}), 5 \mathrm{wt} \%$ poly(tetrafluoroethylene) (PTFE) and few drops of ethanol were homogeneously mixed. After allowing the solvent to evaporate, the resulting paste was pressed onto the foamed nickel current collector with an area of $1 \mathrm{~cm}^{2}$ at $10 \mathrm{MPa}$. These carbon electrodes were dried at $60^{\circ} \mathrm{C}$ for $12 \mathrm{~h}$ under vacuum. Before recording the data, each CV test was firstly cycled three times to make sure the system reached a steady sate.

Capacitance calculations. The specific capacitance $C\left(\mathrm{Fg}^{-1}\right)$ of $\mathrm{CV}$ curves was calculated by integration of current with respect to time, i.e., equation (1):

$$
C=\frac{\int_{0}^{V / s} j \mathrm{dt}}{V}
$$

where $j$ is the gravimetric current density $\left(\mathrm{A} \mathrm{g}^{-1}\right), s$ is the scan rate $\left(\mathrm{V} \mathrm{s}^{-1}\right)$, and $V$ is the potential window $(\mathrm{V})$.

For EQCM measurements, a quartz crystal microbalance (Princeton, QCM922A) system combined with an electrochemical workstation (CHI440C, Shanghai, China) was used for simultaneous EQCM and CV measurements. These electrochemical tests were carried out using a carbon-coated quartz as the working electrode, a platinum foil $\left(1 \times 1 \mathrm{~cm}^{2}\right)$ as the counter electrode, a silver disk as the quasi-reference electrode, and a solution of $0.25 \mathrm{M}$ BMIM-NTf $\mathrm{N}_{2}$ in PC as the electrolyte. The carbon-coated quartz electrode was prepared from YP-50F: $90 \mathrm{wt} \%$ carbon powder, $10 \mathrm{wt} \%$ polyvinylidene fluoride (PVDF) in N-methyl-2- pyrrolidone were homogeneously mixed. This slurry was dripped on an AT-cut gold-coated quartz crystal with a fundamental frequency of $9.00 \mathrm{MHz}$ (the mass loading was $25-50 \mu \mathrm{g} \mathrm{cm}^{-2}$ ), which was then dried at $60^{\circ} \mathrm{C}$ for $12 \mathrm{~h}$ under vacuum (details see Supplementary Information). The corresponding CV tests were carried out at a scan rate of $5 \mathrm{mV} \mathrm{s}^{-1}$ with simultaneous recording of the quartz resonance frequency. Before recording the data, each CV test was firstly cycled three times to make sure the system reached a steady sate.

Data availability. All relevant data supporting the findings of this study are available from the authors on request.

Received: 17 April 2017 Accepted: 10 November 2017 Published online: 19 December 2017

\section{References}

1. Miller, J. R. \& Simon, P. Electrochemical capacitors for energy management. Science 321, 651-652 (2008).

2. Simon, P. \& Gogotsi, Y. Materials for electrochemical capacitors. Nat. Mater. 7, 845-854 (2008)

3. Winter, M. \& Brodd, R. J. What are batteries, fuel cells, and supercapacitors? Chem. Rev. 104, 4245-4270 (2004).

4. Yan, J., Wang, Q., Wei, T. \& Fan, Z. Recent advances in design and fabrication of electrochemical supercapacitors with high energy densities. Adv. Energy Mater. 4, 1300816 (2014).

5. Yang, Z. et al. Recent advancement of nanostructured carbon for energy applications. Chem. Rev. 115, 5159-5223 (2015).

6. Ji, H. et al. Capacitance of carbon-based electrical double-layer capacitors. Nat Commun. 5, 3317 (2014)

7. Béguin, F., Presser, V., Balducci, A. \& Frackowiak, E. Carbons and electrolytes for advanced supercapacitors. Adv. Mater. 26, 2219-2251 (2014).

8. Zhong, C. et al. A review of electrolyte materials and compositions for electrochemical supercapacitors. Chem. Soc. Rev. 44, 7484-7539 (2015).

9. Armand, M., Endres, F., MacFarlane, D. R., Ohno, H. \& Scrosati, B. Ionic-liquid materials for the electrochemical challenges of the future. Nat. Mater. 8, 621-629 (2009).

10. Watanabe, M. et al. Application of ionic liquids to energy storage and conversion materials and devices. Chem. Rev. 117, 7190-7239 (2017).

11. MacFarlane, D. R. et al. Energy applications of ionic liquids. Energy Environ. Sci. 7, 232-250 (2014).

12. Fedorov, M. V. \& Kornyshev, A. A. Ionic liquids at electrified interfaces. Chem. Rev. 114, 2978-3036 (2014).

13. Adam, D. Clean and green...but are they mean? Nature 407, 938-940 (2000).

14. Van Aken, K. L., Beidaghi, M. \& Gogotsi, Y. Formulation of ionic-liquid electrolyte to expand the voltage window of supercapacitors. Angew. Chem. Int. Ed. 54, 4806-4809 (2015).

15. Shi, M., Kou, S. \& Yan, X. Engineering the electrochemical capacitive properties of graphene sheets in ionic-liquid electrolytes by correct selection of anions. ChemSusChem 7, 3053-3062 (2014).

16. Hayes, R., Warr, G. G. \& Atkin, R. Structure and nanostructure in ionic liquids Chem. Rev. 115, 6357-6426 (2015).

17. Zhang, S., Zhang, J., Zhang, Y. \& Deng, Y. Nanoconfined ionic liquids. Chem. Rev. 117, 6755-6833 (2017).

18. Vatamanu, J., Vatamanu, M. \& Bedrov, D. Non-faradaic energy storage by room temperature ionic liquids in nanoporous electrodes. ACS Nano 9, 5999-6017 (2015).

19. Jäckel, N., Simon, P., Gogotsi, Y. \& Presser, V. Increase in capacitance by subnanometer pores in carbon. ACS Energy Lett. 1, 1262-1265 (2016).

20. Lian, C. et al. Enhancing the capacitive performance of electric double-layer capacitors with ionic liquid mixtures. ACS Energy Lett. 1, 21-26 (2016).

21. Varanasi, S. R. \& Bhatia, S. K. Optimal electrode mass ratio in nanoporous carbon electrochemical supercapacitors. J. Phys. Chem. C. 120, 27925-27933 (2016).

22. Forse, A. C., Merlet, C., Griffin, J. M. \& Grey, C. P. New perspectives on the charging mechanisms of supercapacitors. J. Am. Chem. Soc. 138, 5731-5744 (2016).

23. Salanne, M. et al. Efficient storage mechanisms for building better supercapacitors. Nat. Energy 1, 16070 (2016).

24. Wu, P., Huang, J., Meunier, V., Sumpter, B. G. \& Qiao, R. Complex capacitance scaling in ionic liquids-filled nanopores. ACS Nano 5, 9044-9051 (2011).

25. Rajput, N. N., Monk, J. \& Hung, F. R. Structure and dynamics of an ionic liquid confined inside a charged slit graphitic nanopore. J. Phys. Chem. C. 116, 14504-14513 (2012).

26. Merlet, C. et al. On the molecular origin of supercapacitance in nanoporous carbon electrodes. Nat. Mater. 11, 306-310 (2012).

27. Merlet, C. et al. Highly confined ions store charge more efficiently in supercapacitors. Nat. Commun. 4, 2701 (2013). 
28. Kondrat, S., Wu, P., Qiao, R. \& Kornyshev, A. A. Accelerating charging dynamics in subnanometre pores. Nat. Mater. 13, 387-393 (2014).

29. Kondrat, S. \& Kornyshev, A. A. Pressing a spring: what does it take to maximize the energy storage in nanoporous supercapacitors? Nanoscale Horiz. 1, 45-52 (2016).

30. Kondrat, S. \& Kornyshev, A. Charging dynamics and optimization of nanoporous supercapacitors. J. Phys. Chem. C. 117, 12399-12406 (2013).

31. Richey, F. W., Dyatkin, B., Gogotsi, Y. \& Elabd, Y. A. Ion dynamics in porous carbon electrodes in supercapacitors using in situ infrared spectroelectrochemistry. J. Am. Chem. Soc. 135, 12818-12826 (2013).

32. Richey, F. W. \& Elabd, Y. A. In situ molecular level measurements of ion dynamics in an electrochemical capacitor. J. Phys. Chem. Lett. 3, 3297-3301 (2012).

33. Boukhalfa, S. et al. In situ small angle neutron scattering revealing ion sorption in microporous carbon electrical double layer capacitors. ACS Nano 8, 2495-2503 (2014).

34. Bañuelos, J. L. et al. Densification of ionic liquid molecules within a hierarchical nanoporous carbon structure revealed by small-angle scattering and molecular dynamics simulation. Chem. Mater. 26, 1144-1153 (2014).

35. Boukhalfa, S., He, L., Melnichenko, Y. B. \& Yushin, G. Small-angle neutron scattering for in situ probing of ion adsorption inside micropores. Angew. Chem. Int. Ed. 52, 4618-4622 (2013).

36. Levi, M. D., Salitra, G., Levy, N., Aurbach, D. \& Maier, J. Application of a quartz-crystal microbalance to measure ionic fluxes in microporous carbons for energy storage. Nat. Mater. 8, 872-875 (2009).

37. Levi, M. D., Sigalov, S., Aurbach, D. \& Daikhin, L. In situ electrochemical quartz crystal admittance methodology for tracking compositional and mechanical changes in porous carbon electrodes. J. Phys. Chem. C 117, 14876-14889 (2013).

38. Tsai, W. Y., Taberna, P. L. \& Simon, P. Electrochemical quartz crystal microbalance (EQCM) study of ion dynamics in nanoporous carbons. J. Am. Chem. Soc. 136, 8722-8728 (2014).

39. Levi, M. D. et al. Electrochemical quartz crystal microbalance (EQCM) studies of ions and solvents insertion into highly porous activated carbons. J. Am. Chem. Soc. 132, 13220-13222 (2010).

40. Sigalov, S., Levi, M. D., Salitra, G., Aurbach, D. \& Maier, J. EQCM as a unique tool for determination of ionic fluxes in microporous carbons as a function of surface charge distribution. Electrochem. Commun. 12, 1718-1721 (2010).

41. Levi, M. D. et al. In situ porous structure characterization of electrodes for energy storage and conversion by EQCM-D: a review. Electrochim. Acta 232, 271-284 (2017)

42. Levi, M. D., Sigalov, S., Salitra, G., Aurbach, D. \& Maier, J. The effect of specific adsorption of cations and their size on the charge-compensation mechanism in carbon micropores: the role of anion desorption. Chem. Phys. Chem. 12, 854-862 (2011).

43. Shpigel, N. et al. Novel in situ multiharmonic EQCM-D approach to characterize complex carbon pore architectures for capacitive deionization of brackish water. J. Phys. Condens. Matter 28, 114001 (2016).

44. Griffin, J. M. et al. In situ NMR and electrochemical quartz crystal microbalance techniques reveal the structure of the electrical double layer in supercapacitors. Nat. Mater. 14, 812-819 (2015).

45. Blanc, F., Leskes, M. \& Grey, C. P. In situ solid-state NMR spectroscopy of electrochemical cells: batteries, supercapacitors, and fuel cells. Acc. Chem. Res. 46, 1952-1963 (2013).

46. Deschamps, M. et al. Exploring electrolyte organization in supercapacitor electrodes with solid-state NMR. Nat. Mater. 12, 351-358 (2013).
47. Forse, A. C. et al. NMR study of ion dynamics and charge storage in ionic liquid supercapacitors. J. Am. Chem. Soc. 137, 7231-7242 (2015).

48. Forse, A. C. et al. Direct observation of ion dynamics in supercapacitor electrodes using in situ diffusion NMR spectroscopy. Nat. Energy 2, 16216 (2017).

49. Wang, H. et al. In situ NMR spectroscopy of supercapacitors: insight into the charge storage mechanism. J. Am. Chem. Soc. 135, 18968-18980 (2013).

50. Wang, H. et al. Real-time NMR studies of electrochemical double-layer capacitors. J. Am. Chem. Soc. 133, 19270-19273 (2011).

51. Lu, Y., Moganty, S. S., Schaefer, J. L. \& Archer, L. A. Ionic liquid-nanoparticle hybrid electrolytes. J. Mater. Chem. 22, 4066-4072 (2012).

52. Lu, Y., Korf, K., Kambe, Y., Tu, Z. \& Archer, L. A. Ionic-liquid-nanoparticle hybrid electrolytes: applications in lithium metal batteries. Angew. Chem. Int. Ed. 53, 488-492 (2014)

\section{Acknowledgements}

This work was supported by the National Nature Science Foundations of China (21573265 and 21673263)

\section{Author contributions}

X.B.Y. designed this work; Q.Y.D. carried out the organic synthesis and electrochemical experiments; B.J.Y. and J.W.L. made sodium alginate-derived AC; X.B.Y. and Q.Y.D. wrote the paper and analyzed the results. All authors contributed to the discussion of the results.

\section{Additional information}

Supplementary Information accompanies this paper at https://doi.org/10.1038/s41467 017-02152-5.

Competing interests: The authors declare no competing financial interests.

Reprints and permission information is available online at http://npg.nature.com/ reprintsandpermissions/

Publisher's note: Springer Nature remains neutral with regard to jurisdictional claims in published maps and institutional affiliations.

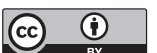

Open Access This article is licensed under a Creative Commons Attribution 4.0 International License, which permits use, sharing, adaptation, distribution and reproduction in any medium or format, as long as you give appropriate credit to the original author(s) and the source, provide a link to the Creative Commons license, and indicate if changes were made. The images or other third party material in this article are included in the article's Creative Commons license, unless indicated otherwise in a credit line to the material. If material is not included in the article's Creative Commons license and your intended use is not permitted by statutory regulation or exceeds the permitted use, you will need to obtain permission directly from the copyright holder. To view a copy of this license, visit http://creativecommons.org/ licenses/by/4.0/.

(c) The Author(s) 2017 